\title{
Surgery guided by 5-aminolevulinic fluorescence in glioblastoma: volumetric analysis of extent of resection in single- center experience
}

Ricardo Díez Valle; Sonia Tejada Solis; Miguel Ángel Idoate Gastearena; Reyes García de Eulate; Pablo Domínguez Echávarri; Javier Aristu Mendiroz

\begin{abstract}
We analyzed the efficacy and applicability of surgery guided by 5-aminolevulinic acid (ALA) fluorescence in consecutive patients with glioblastoma multiforme (GBM). Thirty-six patients with GBM were operated on using ALA fluorescence. Resections were performed using the fluorescent light to assess the right plane of dissection. In each case, biopsies with different fluorescent quality were taken from the tumor center, from the edges, and from the surrounding tissue. These samples were analyzed separately with hematoxylin-eosin examination and immunostaining against Ki67. Tumor volume was quantified with pre- and postoperative volumetric magnetic resonance imaging. Strong fluorescence identified solid tumor with $100 \%$ positive predictive value. Invaded tissue beyond the solid tumor mass was identified by vague fluorescence with $97 \%$ positive predictive value and $66 \%$ negative predictive value, measured against hematoxylin-eosin examination. All the contrast-enhancing volume was resected in $83.3 \%$ of the patients, all patients had resection over $98 \%$ of the volume and mean volume resected was $99.8 \%$. One month after surgery there was no mortality, and new or increased neurological morbidity was $8.2 \%$. The fluorescence induced by 5 aminolevulinic can help to achieve near total resection of enhancing tumor volume in most surgical cases of GBM. It is possible during surgery to obtain separate samples of the infiltrating cells from the tumor border.
\end{abstract}

\section{KEYWORDS}

Glioblastoma; Surgery; 5-aminolevulinic; Volumetric MRI; Gross total resection

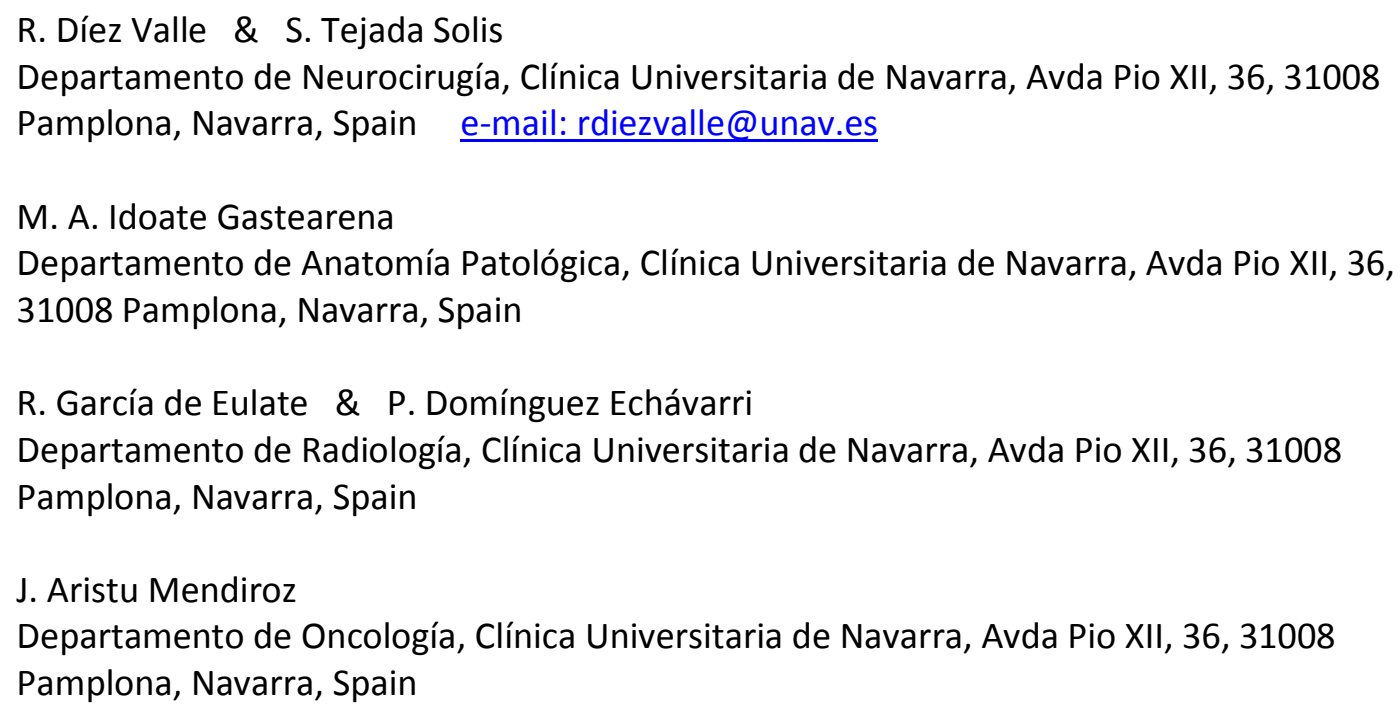




\section{INTRODUCTION}

The value of cytoreductive surgery in GBM is still extensively debated. Most of the recent literature agrees that resection of all the gadolinium-enhancing tumor verified by early magnetic resonance image (MRI) is a predictor of survival, but the evidence is weak, as it is mostly based on retrospective, observational studies [1-3]. The benefit shown could be a consequence of the treatment or the effect of smaller, superficial, noneloquent tumors in younger patients having better prognosis from the beginning and greater resections. However, in 2008, analysis of data from a randomized controlled trial (RCT) using the 5-aminolevulinic (ALA) fluorescence-guided resection (FGR) provided level $2 \mathrm{~b}$ evidence supporting the influence of total resection on survival [4].

Objective measurement of residual tumor after surgery is still missing in many neurooncology trials, and the published rates of gross total resection (GTR) are low. A recent review cited only three papers publishing volumetric analysis of the extent of resection with more than $75 \mathrm{GBM}$ cases [3]. In those studies, the frequency of verified GTR was 21, 33, and 49\% (last figure for resections over $98 \%$ ).

New techniques are needed to improve resection rates. A RCT by the ALA study group in Germany proved the benefit of ALA-induced FGR in GBM [5]. The 65 versus 36\% GTR rate achieved was enough to achieve significance. In this trial, an exclusion criteria was "tumor location did not enable complete resection of contrast-enhancing tumor as decided by individual study surgeon". That criterion can leave some doubt about the applicability of the technique, and residual tumor was still found in $35 \%$ of cases judged to be resectable. We think this does not reflect the true potential of the technique. In that study, some centers performed better, with GTR over $80 \%$ (W. Stummer, personal communication, unpublished data). We studied the applicability and potential of ALA-guided surgery in a series of consecutive patients diagnosed of GBM in our center.

\section{MATERIALS AND METHODS}

From October 2007 to June 2009, we screened for surgery with ALA all patients consulting in our center whose MRI were suggestive of GBM.

Resectability was decided over contrast-enhanced MRI (T1Gd MRI) images. A patient was considered a candidate for surgery if T1Gd MRI showed a definite, unilateral mass not invading thalamus or brain stem. In some cases with small satellite nodules or diffuse enhancing tissue affecting eloquent areas, surgery was advised if more than $90 \%$ of the T1Gd volume could be included in the target volume. Flair and T2 sequences were reviewed for evidence of big diffuse extension, in doubtful and in recurrent cases, C11-methionine positron emission tomography (met-PET) was done to precisely measure the tumor extension.

We excluded from surgery patients with bilateral tumor, multiple distant lesions, subependimal spreading or tumors with small contrast-enhancing lesions and very extensive diffuse component. 
We did not exclude patients with T1Gd-enhancing mass that reached the ventricle or the corpus callosum if it did not have bilateral or subependimal spreading in $\mathrm{T} 1 \mathrm{Gd}$ sequence.

All cases were planned with the Brainlab navigation system. The T1Gd volume was manually segmented in BrainLab station and measured with the iplan cranial 2.6 software. The neurosurgeon responsible for the case drew the abnormal enhancing area in each MRI slice; the final volume included all the enhancing area and the necrotic tissue within it. This was the preoperative tumor volume used in the volumetric calculations. In two cases, the target for surgery excluded small parts $(0.25$ and $0.2 \mathrm{ml})$ of the enhancing volume.

We counted as newly diagnosed GBM cases the patients receiving their first operation or having a previous biopsy or partial resection in another center, but no previous radiotherapy nor chemotherapy, Patients with tumors recurrent after at least radiotherapy or chemotherapy treatment were grouped as recurrent GBM.

The patient management was standard except for the oral administration of $20 \mathrm{mg} / \mathrm{kg} \mathrm{5-}$ aminolevulinic acid 2-4 h before surgery, as published [6]. All surgeries were performed with a Zeiss Pentero microscope equipped with a fluorescent $400 \mathrm{~nm}$ UV light and filters. BrainLab navigation was used in every case, but when PET was available, the met-PET was fused to the MRI in the Brainlab station and both MRI and PET were used during surgery. Intraoperative MRI was not used.

In all cases, we worked following the border of the tumor, keeping the dissection just outside it. We performed debulking of the tumor only if it was necessary to achieve a relaxed brain. When possible, we evacuated CSF from arachnoid cisterns before doing debulking. In cases that needed debulking, we went back to the border dissection as soon as the brain was relaxed enough. Ultrasonic aspiration was not used. We worked most of the time under the normal white light, but switched frequently to the UV light to assess the limit of the tumor with the fluorescent light and establish the right dissection plane.

During surgery, we used the different fluorescent qualities described previously [7]: solid fluorescence (bright red), vague fluorescence (shades of pink) and non-fluorescent tissue (blue), to obtain separate samples from the center of the tumor, from the vague fluorescence regions at the edges of the tumor, and from the non-fluorescent tissue adjacent to it (Fig. 1b, c). These samples were sent for separate analysis including optical microscope examination and Ki67. In all cases, at least one sample was taken from the most peripheral part of tumor shown, the last fluorescent millimeters, and from the first millimeters of normal looking tissue. One experienced neuropathologist (M.I.G.), who was blinded to the fluorescent or non-fluorescent quality of the tissue, analyzed all the samples. This study includes only the patients diagnosed of GBM by WHO criteria.

We obtained pre- and post-contrast MRI less than $72 \mathrm{~h}$ after surgery in every case, most cases before $36 \mathrm{~h}$. Post-operative MRI was exported to the Brainlab station, and precontrast and postcontrast T1 images were compared. Although the diffuse nature of GBM is well known, the previous work on the benefit of surgical resection has been made using the T1Gd volume, which is the present target of surgery, so we used only 
this volume. Enhancing areas were considered tumor except for obvious vessel images. The residual tumor volume was segmented manually in each slice and measured by the iplan cranial 2.6 software.

Two neuroradiologists (R.G.E. and P.D.E.) measured the residual tumor. Mean interobserver difference in the residual tumor volume measurements was $0.14 \mathrm{ml}(0-1.9$ $\mathrm{ml})$, the mean interobserver variability was $56 \%$ of the residual tumor volume. The mean variability amounts to $0.2 \%$ of the preoperative volume. After review of the discrepancies, both observers agreed in the cases which were considered GTR; the mean of both measurements was used for the rest. Resection was calculated as percent change of residual tumor over preoperative $\mathrm{T} 1 \mathrm{Gd}$ volume in all cases.

Neurological evaluation was used to measure clinical status before surgery, at 1 week and 1 month after surgery.

After surgery, first-line patients received radiotherapy plus temozolomide treatment, except patient no. 9 who refused. Recurrent patients and most first-line at progression received irinotecan plus bevacizumab. No patient had reoperation.

All patients gave informed consent for the study procedure.

\section{RESULTS}

\section{Surgery}

Of the patient with suspected high grade glioma evaluated by the recruiting neurosurgeons during the study period, 7 patients had biopsy only (4 GBM, 2 limphoma, 1 anaplastic astrocitoma), and 42 had resection surgery. Of 42 patients undergoing resection, 36 were GBM and are the basis for this report, while 6 had different grade three gliomas. In total, $90 \%$ of all the GBM underwent resection surgery. Of the 36 cases, 28 were newly diagnosed cases and 8 patients had recurrent tumors. Table 1 summarizes the clinical data of the patients.

We could differentiate in all cases the three different fluorescent qualities, with neat distinction of the solid mass of the tumor in bright red, and the border in shades of pink. The pink areas were variable from one case to another and from some regions of the tumor to others, but in every case, some border area could be identified. In the tumors that reached the ventricle, there was always a wide surrounding pink area and the ventricular wall was at least partly fluorescent. The recurrent tumors had wider pink areas and less intense bright in the center. When radionecrosis was present, bright spots of viable tissue were mixed with necrotic, non-fluorescent tissue.

\section{Histology}

Table 2 summarizes the pathological diagnosis of the samples. A total of 72 samples with bright, red fluorescence were analyzed and corresponded always to solid tumor with the diagnostic criteria of GBM. A total of 73 samples from the edge of the pink 
areas were analyzed. In 2 small samples with very slight fluorescence from the same patient, the tissue was normal. In the remaining 71, the tissue was abnormal and $90 \%$ of the times, these areas had pathological features different from the core of the tumor. The biopsies were included in one spectrum going from highly cellular, with mitosis and atypical features, to only a slight increase in cellularity (Fig. 1d). The tumor cells at the edge looked less atypical than the tumor cells in the center of the lesion. Taken out of context, these would have been diagnosed as low grade astrocytoma.

A total of 36 samples were taken from the non-fluorescent tissue adjacent to the last fluorescent pieces. It was difficult to assess the presence of tumor in these areas, and $66 \%$ were diagnosed as normal tissue by routine hematoxylin-eosin. In the pathological $33 \%$, the tissue was classified as abnormal on the basis of isolated atypical cells or a slight increase in cell density (Fig. 1f).

Using hematoxylin-eosin as the gold standard, red samples had $100 \%$ positive predictive value (PPV) for solid tumor, pink samples 97\% PPV for tumor, and nonfluorescent samples had 66\% negative predictive value (NPV) for tumor. There was significant correlation between fluorescence and histology with $\mathrm{P}<0.001$ by Spearman test.

\section{Immunohistochemical study}

Proliferative index was assessed by Ki 67 (Fig. 1g-i). The index of marked cells was 23.94 [confidence intervals (CI) 95\% 15-33) in the central areas; 6.23 (CI 95\% 4-9) in the vague fluorescence areas; and 1.67 (CI 95\% 0.9-2.5)] in the blue areas. The differences between red and pink and pink and blue areas were significant at $\mathrm{P}<0.001$ by $t$ test (Fig. 2). Only 31\% of the normal-looking areas were negative with Ki 67 .

\section{Radiology}

The mean preoperative tumor volume was $51.18 \mathrm{ml}(7.3-110)$. Total resection was achieved in $83.3 \%$ of the cases (30/36). The resection was greater than $98 \%$ of preoperative tumor volume in all the cases. Mean resection in the 36 patients was $99.8 \%$. The mean postoperative tumor volume in the six cases with remnants was $0.56 \mathrm{ml}$ (0.21-1.8). Figure 3 shows some illustrative cases.

\section{Safety}

There was no mortality at 1 month in our series. We had a new neurological deficit after surgery in $11.1 \%$ of our patients, and another $13.8 \%$ had worsening of a previous deficit. At 1 month, six out of these nine patients had recovered and only three patients $(8.2 \%)$ were worse than before surgery, while $13(36.1 \%)$ had recovered from preoperative deficits, and were better than before (Table 3). The new deficits at 1 month were a left hemiparesis, a left leg paresis and a dysphasia. 


\section{Survival}

Mean KPS was 70 and mean age was 58. Cumulative survival duration and progressionfree survival from the time of surgery at our institution was computed using the Kaplan-Meier method. Survival was analyzed separately for first treatment and recurrent cases. Mean progression-free survival for newly diagnosed GBM was 6.5 months (95\% CI 3.8-9.2) and for recurrent cases 5.3 months (95\% CI 4.4-6.2), Fig. 4 shows the Kaplan-Meier curve. Median survival for newly diagnosed GBM was 15.7 months (95\% CI 5.3-26.1) and for recurrent GBM, 7.9 months (95\% CI 7.2-18.4), Fig. 5 shows the Kaplan- Meier curve.

\section{DISCUSSION}

Despite limitations in the quality of data, growing evidence suggests that more extensive surgical resection is associated with longer life expectancy for GBMs in retrospective papers [1, 2], literature review, [3] and a cohort study [4]. Volumetric analysis suggests that resection correlates with longer survival only if it exceeds $90 \%$ of tumor volume measured as $\mathrm{T} 1 \mathrm{Gd}$, and the benefit is maximal when resection is more than 98\% [2]. Data from the EORTC-NCIC trial show that the benefit from radiotherapy (RT) plus temozolomide (TMZ) is greater in patients with GTR [8].

GTR should be the goal in every patient, if it can be done with a low risk of permanent neurological deficit. Early MRI should be performed in every case, to provide an adequate prognosis for the individual and to stratify patients properly in clinical trials for new therapies. A recent review [3] cited only three papers with volumetric measurement of residual tumor by post-operative MRI, and more than 75 cases with frequency of verified total resection of 23\% [9], 33\% [10], and 49\% (this for resections over $98 \%$ of tumor volume) [2]. Other studies with resection measured by postoperative MRI, but smaller number of cases or non-volumetric analysis, have published similar rates of GTR, with best rates around $35 \%[11,12]$, so a majority of the patients do not get GTR. This leaves the question as to how to improve the rate of GTR.

Fluorescence-guided resection of GBM using ALA is a technique developed in 1998 [6, 7]. Using ALA FGR offers real time viewing of the tumor in the operative field so we thought this system should allow us to resect almost all the tumor in most cases. Our results support this hypothesis as $83 \%$ of our patients had no residual tumor, mean volume resected was $99.8 \%$, and all our patients got more than $98 \%$ resection, the limit for maximum benefit found in the largest series to date [2]. Our patients are representative of a good number of GBM cases, as the only criteria for inclusion in this study was resection surgery and the criteria for surgery used were wide. We tried to use indications for resection which were wide and reproducible, although a totally objective evaluation is not possible. Only $10 \%$ of the cases in the study period had not had resection surgery. We are a private center in a country with free public health care and many of our patients are second opinion cases rejected for surgery in other hospitals. The mean volume was $51 \mathrm{ml}$, mean KPS was 70 and mean age was 58, so this was not an especially favorable group of patients.

We made a parallel pathological study to verify the correlation of fluorescence and histology. The 100\% positive predictive value (PPV) for solid tumor, 97\% PPV for 
invasive areas in the border, and 66\% negative predictive value (NPV) of nonfluorescent tissue, provides a rational, very solid foundation for the efficacy of the technique. We found no significant difference in biopsies of recurrent tumors; a recent paper also found a good correlation in recurrence [13]. The neurosurgeon can be sure that all the bright red tissue is solid tumor, without normal parenchyma so it can be resected, even near eloquent areas, and the vague fluorescence areas correspond with areas where tumor cells infiltrate brain tissue, the interface between tumor and brain. In eloquent areas. This vague fluorescence was not resected, and mostly was not visible in postoperative-MRI, as published previously [6], suggesting that vague fluorescent tissue is outside the gadolinium-enhancing border of the tumor.

For the first time, the neurosurgeons have a tool which allows them to see the border of heavy infiltration, and these areas can be resected where not eloquent, which could allow for more extensive GTR that the actual standard targeting of the T1Gd area. It remains to be seen whether this extended GTR will give some additional benefit regarding survival. A recent report found that GTR verified by PET can impact survival more than total GTR verified by MRI [14]. A correlation may exist between ALA fluorescence and amino acid-PET [15].

In our non-fluorescent biopsies, the $66 \%$ NPV changed dramatically when we studied the samples with Ki-67 showing tumor cells beyond our "extended GTR" in 69\% of the cases. This reminds us that any surgical border in GBM is going to leave residual cells. The invasive cells surrounded by normal tissue are different from the center so the response to treatment could be different [16]. To be successful, any adjuvant therapy should target these remaining cells. The ability to see the border also offers an opportunity for selective sampling of the invading cells in good quantity and in all cases. The study of these cells could offer new insights into the mechanism of this disease.

This study was not designed to evaluate survival, yet the data of PFS and OS compare favorably with reference series in GBM [17].

Greater resections can entail increased risk for the patient. With ALA fluorescence, we actually "see" the tumor, including diffuse infiltrating areas where the tumor cells mix with normal brain. We do not think fluorescence here is a problem but an advantage; this is an old problem for neurosurgeons which is improved by a new tool, which helps them to know which areas are solid tumor and which are diffuse invasion. If the tumor approaches an eloquent area, the vague fluorescence should be left behind or the surgery may be performed cautiously with neurophysiological monitoring, which can be used at the same time that ALA surgery with good results [18]. Our immediate neurological morbidity was high at $25 \%$, but the majority of the deficits were transitory; at 1 month, it was $8.2 \%$. In the Glioma Outcome Project, neurological morbidity at 21 days was $8.1 \%$ for first craniotomy and $18 \%$ for second [19]. Having more complete resection allows for less edema and less risk of bleeding postoperatively; we did not have any postoperative bleeding, postoperative symptomatic edema, or new postoperative seizures.

Neurosurgeons have looked for years for techniques to see the tumor in the field, most of which have never achieved wide usage. To our knowledge, this is the only system 
tried in a randomized study. At this moment, FGR could be compared to intraoperative MRI (iMRI) and to other tumor-staining techniques.

Using iMRI with low field iMRI, 22 out of 28 GBM patients $(78 \%)$ had GTR in a recent report [20]. Mean volumetric resection of 94\% [21] and 99\% in GBM [22] have been achieved with high field magnets. A comparison between iMRI and FGR with evaluation of benefit and cost of each system would be interesting but is beyond the scope of this paper.

Recent reports have given credit to two other fluorescent systems, sodium fluorescein and 5-aminofluorescein coupled to albumin. Fluorescein sodium has been used with encouraging results, although no randomized study has been completed [23-25]. In high doses, this has the advantage of not requiring special equipment. The authors have reported GTR rates of $83 \%$ [24], and 84\% [25], but in selected cases and without volumetric data on the residues. The histological data are poor, since only four patients are included, and this technique is found to be less precise than ALA in visualizing the invasive border versus the "normal" area around the tumor.

In the report on the use of 5-aminofluorescein-labeled albumin, the authors claim that their $81.8 \%$ GTR rate compares very favorably with the earlier $65 \%$ found in the RCT concerning ALA. Their data have only 10 GBM cases with $70 \%$ verified resection and 1 case with control MRI not done. The present data compare favorably in resection, and in particular, the correlation with the histology results is much greater [26].

\section{CONCLUSIONS}

With the limitations of the small size and single center nature of our data, the fluorescence produced by 5-aminolevulinic is a highly efficient and safe method of achieving maximal safe resection of GBM. Using this system, a majority of patients could have GTR, the only tumor remnants should be very small areas near eloquent tissue.

With this technique, it is possible to obtain separate samples of the infiltrating cells of the border of the tumor during every surgery, which could be useful for new treatments needed in this disease.

\section{REFERENCES}

1. Albert FK, Forsting M, Sartor K, Adams H, Kunze S (1994) Early postoperative magnetic resonance imaging after resection of malignant glioma: objective evaluation of residual tumor and its influence on regrowth and prognosis. Neurosurgery 34:45-61.

2. Lacroix M, Abi-Said D, Fourney DR, Gokaslan ZL, Shi W, DeMonte F, Lang F, McCutcheon I, Hassenbusch S, Holland E, Hess K, Michael C, Miller D, Sawaya R (2001) A multivariate analysis of 416 patients with glioblastoma multiforme: prognosis, extent of resection, and survival. J Neurosurg 95:190198. 
3. Sanai N, Berger MS (2008) Glioma extent of resection and its impact on patient outcome. Neurosurgery 62:753-764.

4. Stummer W, Reulen H7, Meinel T, Pichlmeier U, Schumacher W, Tonn JC et al (2008) Extent of resection and survival in glioblastoma multiforme: identification of and adjustment for bias. Neurosurgery 62:564-576.

5. Stummer W, Pichlmeier U, Meinel T, Wiestler OD, Zanella F, Reulen HJ, for the ALA-glioma Study Group (2006) Fluorescence-guided surgery with 5aminolevulinic acid for resection of malignant glioma: a randomised controlled multicentre phase III trial. Lancet Oncol 7:392-401.

6. Stummer W, Novotny A, Stepp H, Goetz C, Bise K, Reulen HJ (2000) Fluorescence-guided resection of glioblastoma multiforme by using 5aminolevulinic acid-induced porphyrins: a prospective study in 52 consecutive patients. J Neurosurg 93:1003-1013.

7. Stummer W, Stocker S, Wagner S, Stepp H, Fritsch C, Goetz C et al (1998) Intraoperative detection of malignant gliomas by 5 -aminolevulinic acid-induced porphyrin fluorescence. Neurosurgery 42:518-525 (discussion 525-6).

8. Stupp R, Hegi ME, Mason WP, van den Bent MJ, Taphoorn M7, 7anzer RC et al (2009) Effects of radiotherapy with concomitant and adjuvant temozolomide versus radiotherapy alone on survival in glioblastoma in a randomised phase III study: 5-year analysis of the EORTC-NCIC trial. Lancet Oncol 10:459-466.

9. Keles GE, Anderson B, Berger MS (1999) The effect of extent of resection on time to tumor progression and survival in patients with glioblastoma multiforme of the cerebral hemisphere. Surg Neurol 52:371-379.

10. Pope WB, Sayre J, Perlina A, Villablanca 7P, Mischel PS, Cloughesy TF (2005) MR imaging correlates of survival in patients with high-grade gliomas. A7NR Am J Neuroradiol 26:2466-2474.

11. Ushio Y, Kochi M, Hamada J, Kai Y, Nakamura H (2005) Effect of surgical removal on survival and quality of life in patients with supratentorial glioblastoma. Neurol Med Chir (Tokyo) 45:454- 460 (discussion 460-1).

12. McGirt MJ, Chaichana KL, Gathinji M, Attenello FJ, Than K, Olivi A et al (2009) Independent association of extent of resection with survival in patients with malignant brain astrocytoma. J Neurosurg 110:156-162.

13. Nabavi A, Thurm H, Zountsas B, Pietsch T, Lanfermann H, Pichlmeier U et al (2009) Five-aminolevulinic acid for fluorescence-guided resection of recurrent malignant gliomas: a phase ii study. Neurosurgery 65:1070-1076 (discussion 1076-7).

14. Pirotte BJ, Levivier M, Goldman S, Massager N, Wikler D, Dewitte O et al (2009) Positron emission tomography-guided volumetric resection of supratentorial high-grade gliomas: a survival analysis in 66 consecutive patients. Neurosurgery 64: 471-481. doi:10.1227/01.NEU.0000338949.94496.85 (discussion 481).

15. Stockhammer F, Misch M, Horn P, Koch A, Fonyuy N, Plotkin M (2009) Association of F18-fluoro-ethyl-tyrosin uptake and 5-aminolevulinic acidinduced fluorescence in gliomas. Acta Neurochir (Wien) 151:1377-1383.

16. Giese A, Bjerkvig R, Berens ME, Westphal M (2003) Cost of migration: invasion of malignant gliomas and implications for treatment. J Clin Oncol 21:1624-1636.

17. Stupp R, Mason WP, van den Bent MJ, Weller M, Fisher B, Taphoorn MJ et al (2005) Radiotherapy plus concomitant and adjuvant temozolomide for glioblastoma. N Engl J Med 352:987- 996. 
18. Feigl G, Ritz R, Moraes M, Klein J, Ramina K, Gharabaghi A et al (2009) Resection of malignant brain tumors in eloquent cortical areas: a new multimodal approach combining 5-aminolevulinic acid and intraoperative monitoring. J Neurosurg (in press).

19. Chang S, Parney I, McDermott M, Barker F, Schmidt M, Huang W et al (2003) Perioperative complications and neurological outcomes of first and second craniotomies among patients enrolled in the glioma outcome project. J Neurosurg 98:1175.

20. Senft C, Seifert V, Hermann E, Franz K, Gasser T (2008) Usefulness of intraoperative ultra low-field magnetic resonance imaging in glioma surgery. Neurosurgery 63:257-267.

21. Lenaburg H, Inkabi K, Vitaz T (2009) The use of intraoperative MRI for the treatment of glioblastoma multiforme. Technol Cancer Res Treat 8:159.

22. Hatiboglu MA, Weinberg JS, Suki D, Rao G, Prabhu S, Shah K, Jackson E, Sawaya R (2009) Impact of intraoperative high-field magnetic resonance imaging guidance on glioma surgery: a prospective volumetric analysis. Neurosurgery 64(suppl. 6):1073-1081 (discussion 1081).

23. Kuroiwa T, Kajimoto Y, Ohta T (1998) Development of a fluorescein operative microscope for use during malignant glioma surgery: a technical note and preliminary report. Surg Neurol 50:41-48 (discussion 48-9)

24. Shinoda J, Yano H, Yoshimura S, Okumura A, Kaku Y, Iwama T et al (2003) Fluorescence-guided resection of glioblastoma multiforme by using high-dose fluorescein sodium. Technical note. J Neurosurg 99:597-603.

25. Koc K, Anik I, Cabuk B, Ceylan S (2008) Fluorescein sodium-guided surgery in glioblastoma multiforme: a prospective evaluation. Br J Neurosurg 22:99-103.

26. Kremer P, Mahmoudreza F, Ding R, Pritsch M, Zoubaa S, Frei E (2009) Intraoperative fluorescence staining of malignant brain tumors using 5aminofluorescein-labeled albumin. Neurosurgery 64:53-60 (discussion 60-61). 
Table 1. Summary of clinical data

\begin{tabular}{|c|c|c|c|c|c|c|c|c|c|c|c|}
\hline No. & Diagnosis & Age & KPS & $\begin{array}{c}\text { Functional } \\
\text { location } \\
\text { grade }^{\mathbf{a}}\end{array}$ & $\begin{array}{c}\text { Resection } \\
(\%)\end{array}$ & $\begin{array}{l}\text { Residual } \\
\text { tumor cc }\end{array}$ & Follow-up & PFS & OS & Status ${ }^{b}$ & $\begin{array}{l}\text { Adjuvant } \\
\text { therapy }^{\text {c }}\end{array}$ \\
\hline 1 & GBM & 59 & 60 & I & 100 & 0 & 29.6 & 5.3 & 9.4 & $\mathrm{DD}$ & $\mathrm{R}, \mathrm{T}$ \\
\hline 2 & GBM & 67 & 80 & II & 100 & 0 & 28.9 & 6.4 & 6.4 & DO & $\mathrm{R}, \mathrm{T}$ \\
\hline 3 & GBM & 57 & 30 & III & 100 & 0 & 27.2 & 5.8 & 6.7 & DD & $\mathrm{R}, \mathrm{IB}^{\mathrm{e}}$ \\
\hline 4 & GBM & 34 & 90 & I & 100 & 0 & 25.9 & 4.7 & 7.7 & DD & $\mathrm{R}, \mathrm{T}, \mathrm{IB}$ \\
\hline 5 & GBM & 61 & 80 & II & 100 & 0 & 25.6 & 16.8 & 20.8 & $\mathrm{DD}$ & $\mathrm{R}, \mathrm{T}$ \\
\hline 6 & R. GBM & 57 & 70 & II & 100 & 0 & 24.7 & 5.0 & 5.0 & DD & IB \\
\hline 7 & R. GBM & 61 & 70 & I & 100 & 0 & 23.6 & 10.0 & 13.0 & $\mathrm{DD}$ & $\mathrm{T}^{\mathrm{d}}$ \\
\hline 8 & GBM & 72 & 70 & II & 100 & 0 & 23.1 & 6.5 & 6.5 & DD & d \\
\hline 9 & GBM & 69 & 90 & II & 100 & 0 & 22.6 & $>22.6$ & $>22.6$ & PFS & $\mathrm{R}, \mathrm{T}$ \\
\hline 10 & GBM & 36 & 40 & III & 100 & 0 & 22.5 & 8.4 & 15.7 & $\mathrm{DD}$ & $\mathrm{R}, \mathrm{T}, \mathrm{IB}$ \\
\hline 11 & GBM & 71 & 70 & III & 100 & 0 & 21.9 & $>21.9$ & $>21.9$ & PFS & $\mathrm{R}, \mathrm{T}$ \\
\hline 12 & GBM & 72 & 70 & II & 99.8 & 0.2 & 21.2 & 14.2 & $>21.2$ & PD & $\mathrm{R}, \mathrm{T}, \mathrm{IB}$ \\
\hline 13 & R. GBM & 47 & 80 & II & 100 & 0 & 21.2 & 6.6 & 7.4 & DD & IB \\
\hline 14 & GBM & 52 & 50 & III & 100 & 0 & 19.8 & 6.4 & 8.0 & DD & $\mathrm{R}, \mathrm{T}$ \\
\hline 15 & R. GBM & 66 & 90 & III & 100 & 0 & 19.8 & 3.7 & 3.7 & DO & IB \\
\hline 16 & R. GBM & 43 & 80 & II & 98.6 & 0.9 & 18.2 & 5.3 & 15.6 & DD & $\mathrm{T}, \mathrm{IB}$ \\
\hline 17 & GBM & 49 & 100 & II & 100 & 0 & 17.3 & $>17.3$ & $>17.3$ & PFS & $\mathrm{R}, \mathrm{T}$ \\
\hline 18 & R. GBM & 62 & 40 & II & 100 & 0 & 16.3 & 1.1 & 1.1 & $\mathrm{DO}$ & f \\
\hline 19 & GBM & 53 & 90 & II & 100 & 0 & 15.5 & 3.1 & $>15.5$ & PD & $\mathrm{R}, \mathrm{T}, \mathrm{IB}$ \\
\hline 20 & GBM & 63 & 70 & II & 98.5 & 0.3 & 15.0 & 14.7 & $>15$ & PD & $\mathrm{R}, \mathrm{T}$ \\
\hline 21 & GBM & 30 & 60 & II & 100 & 0 & 14.7 & $>14.7$ & $>14.7$ & PFS & $\mathrm{R}, \mathrm{T}$ \\
\hline 22 & GBM & 69 & 70 & I & 100 & 0 & 14.4 & 4.4 & 4.4 & DO & $\mathrm{R}, \mathrm{T}$ \\
\hline 23 & GBM & 63 & 60 & II & 98.3 & 1.8 & 14.2 & 14.2 & 14.2 & PFS & $\mathrm{R}, \mathrm{T}$ \\
\hline 24 & R. GBM & 55 & 100 & I & 100 & 0 & 13.3 & 1.9 & 9.6 & $\mathrm{DD}$ & $\mathrm{T}, \mathrm{IB}$ \\
\hline 25 & GBM & 48 & 40 & III & 100 & 0 & 12.6 & 4.7 & $>12.6$ & PD & $\mathrm{R}, \mathrm{T}, \mathrm{IB}$ \\
\hline 26 & GBM & 70 & 90 & II & 100 & 0 & 11.2 & 5.9 & 6.6 & DD & $\mathrm{R}, \mathrm{T}^{\mathrm{e}}$ \\
\hline 27 & GBM & 69 & 70 & II & 100 & 0 & 11.0 & $>11$ & $>11$ & PFS & $\mathrm{R}, \mathrm{T}$ \\
\hline 28 & R. GBM & 59 & 60 & III & 100 & 0 & 10.3 & 5.6 & 7.9 & DD & $\mathrm{T}, \mathrm{IB}$ \\
\hline 29 & GBM & 59 & 80 & III & 100 & 0 & 10.0 & 4.7 & $>10$ & PD & $\mathrm{R}, \mathrm{T}, \mathrm{IB}$ \\
\hline 30 & GBM & 73 & 70 & III & 99.3 & 0.25 & 7.5 & 3.1 & $>7.5$ & PD & $\mathrm{R}, \mathrm{T}, \mathrm{IB}$ \\
\hline 31 & GBM & 71 & 40 & III & 100 & 0 & 6.8 & 1.1 & 1.1 & DO & $\mathrm{f}$ \\
\hline 32 & GBM & 50 & 80 & III & 98.5 & 0.2 & 7.1 & $>7.1$ & $>7.1$ & PFS & $\mathrm{R}, \mathrm{T}$ \\
\hline 33 & GBM & 67 & 60 & II & 100 & 0 & 6.4 & $>6.4$ & $>6.4$ & PFS & $\mathrm{R}, \mathrm{T}$ \\
\hline 34 & GBM & 57 & 80 & I & 100 & 0 & 6.3 & $>6.3$ & $>6.3$ & PFS & $\mathrm{R}, \mathrm{T}$ \\
\hline 35 & GBM & 43 & 70 & I & 100 & 0 & 6.1 & $>6.1$ & $>6.1$ & PFS & $\mathrm{R}, \mathrm{T}$ \\
\hline 36 & GBM & 67 & 80 & II & 100 & 0 & 6.0 & $>6.0$ & $>6.0$ & PFS & $\mathrm{R}, \mathrm{T}$ \\
\hline
\end{tabular}

R. GBM Recurrent glioblastoma

${ }^{\mathrm{a}}$ Functional location grade according to Sawaya: I non-eloquent brain, II near eloquent, and III eloquent

${ }^{\mathrm{b}}$ Status at last follow-up: DD death from disease, DO death from other causes, PD progressive disease, PFS progression-free survival

${ }^{c}$ Adjuvant therapy: $\mathrm{R}$ radiotherapy, $\mathrm{T}$ temozolomide, IB irinotecan + bevacizumab

${ }^{\mathrm{d}}$ Refused all or part of the treatment

${ }^{\mathrm{e}}$ Could not tolerate temozolomide

${ }^{\mathrm{f}}$ Death of associated problems before adjuvant therapy 


\begin{tabular}{|c|c|c|c|}
\hline \multicolumn{4}{|c|}{ Table 2. Histological results } \\
\hline Histological diagnosis $^{\mathrm{a}}$ & $\begin{array}{l}\text { Strong } \\
\text { fluorescence* } \\
\text { (bright red) } \\
\text { n }(\%)\end{array}$ & $\begin{array}{l}\text { Vague } \\
\text { fluorescence* } \\
\quad(\text { pink) } \\
\text { n }(\%)\end{array}$ & $\begin{array}{l}\text { No fluorescence* } \\
\text { (blue) } \\
\text { n }(\%)\end{array}$ \\
\hline Glioblastoma & $72(100 \%)$ & $5(6.9 \%)$ & 0 \\
\hline $\begin{array}{l}\text { Astrocytic neoplasia (without } \\
\text { criteria for grade } 4 \text { ) }\end{array}$ & 0 & $65(90.3 \%)$ & $12(33 \%$ \\
\hline Normal & 0 & $2(2.8 \%)$ & $24(66 \%)$ \\
\hline \multicolumn{4}{|c|}{$\begin{array}{l}{ }^{a} \text { Diagnosis based on Hematoxylin-eosin staning } \\
* \mathrm{P}<0.001 \text { for the difference between strong and vague fluorescence and between vague and } \\
\text { no fluorescence (Mann-Whitney) }\end{array}$} \\
\hline
\end{tabular}



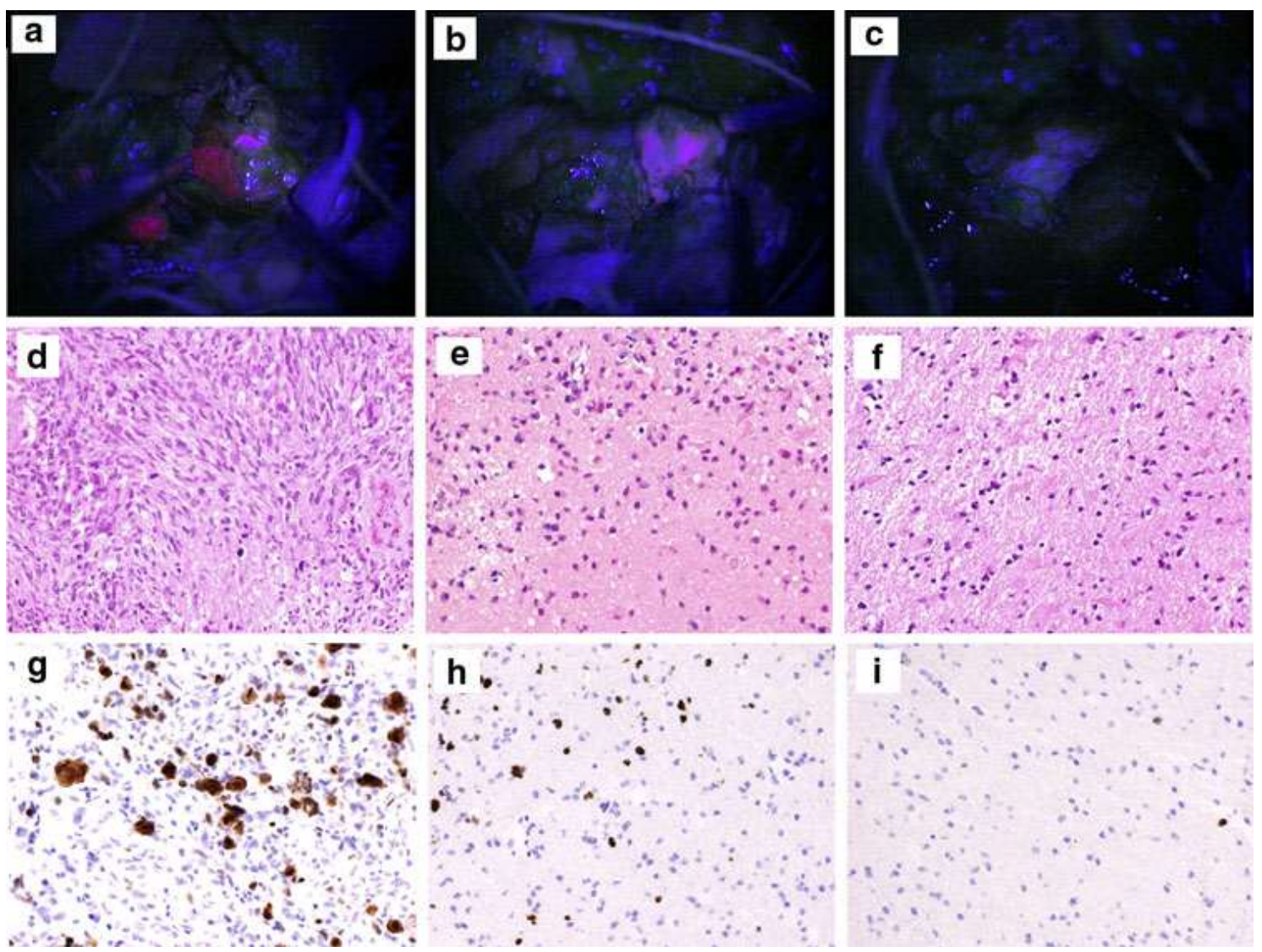

Figure 1. The three columns show the different qualities of tissue with fluorescent light. Upper row, surgical microscope photographs of: a bright fluorescence, b vague fluorescence, and c no fluorescence; in lower rows, the corresponding histology (d-f) and ki67 for the same section $(\mathrm{g}-\mathrm{i})$.

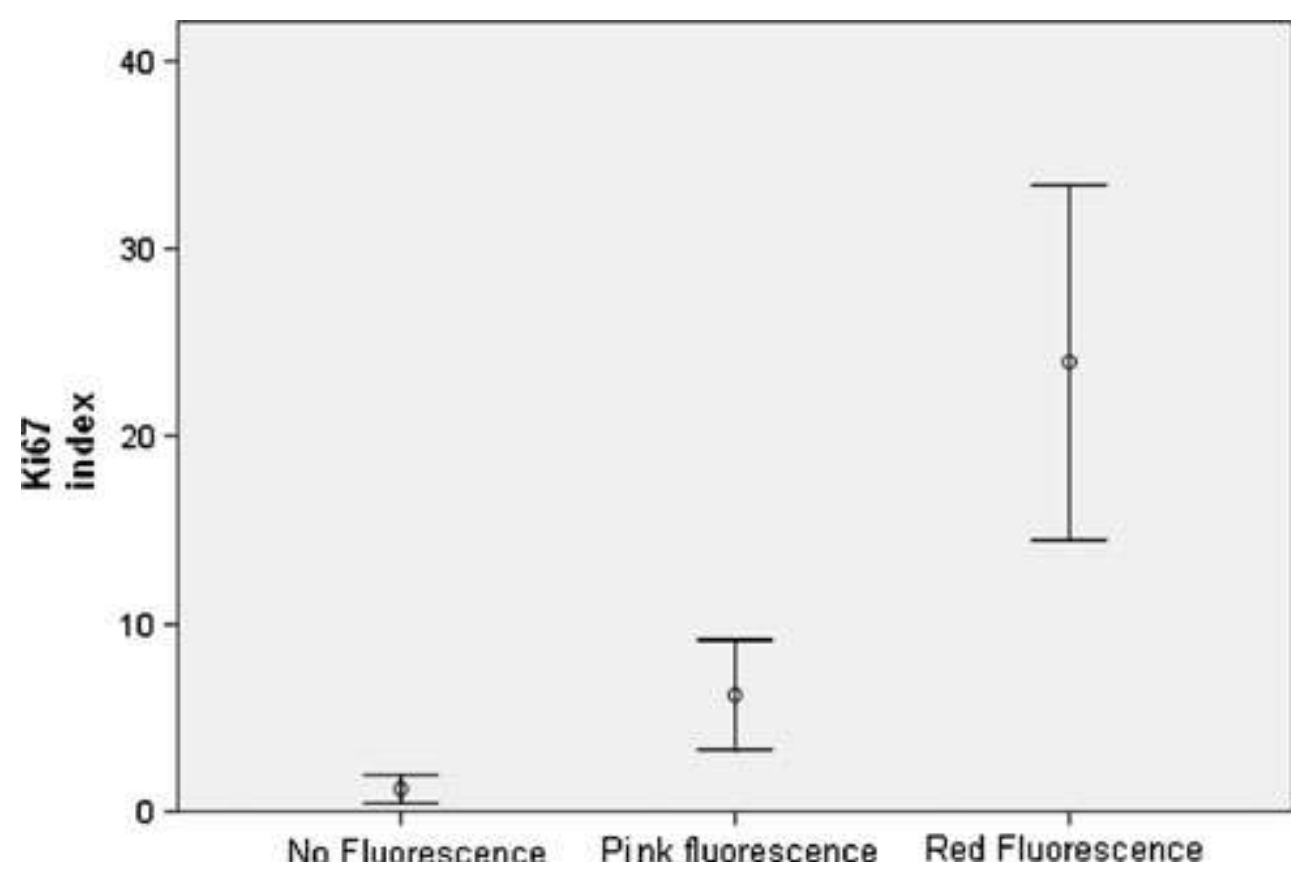

Figure 2. Ki67 labeling index for the different fluorescent qualities. Bars show mean and CI $95 \%$. 


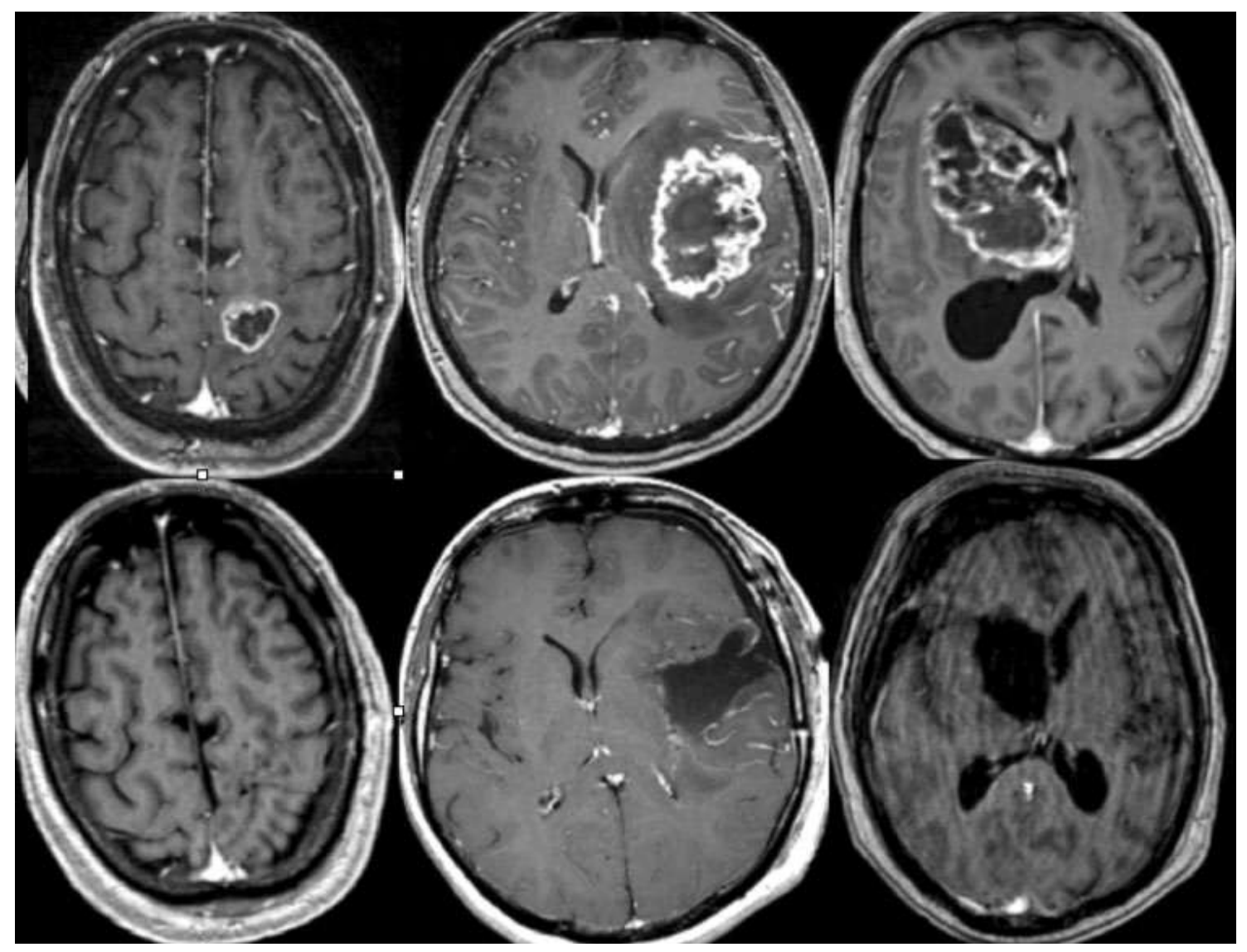

Figure 3. Pre and postoperative MRI of some illustrative cases. From left to right, patient numbers 11,10 and 3 . 


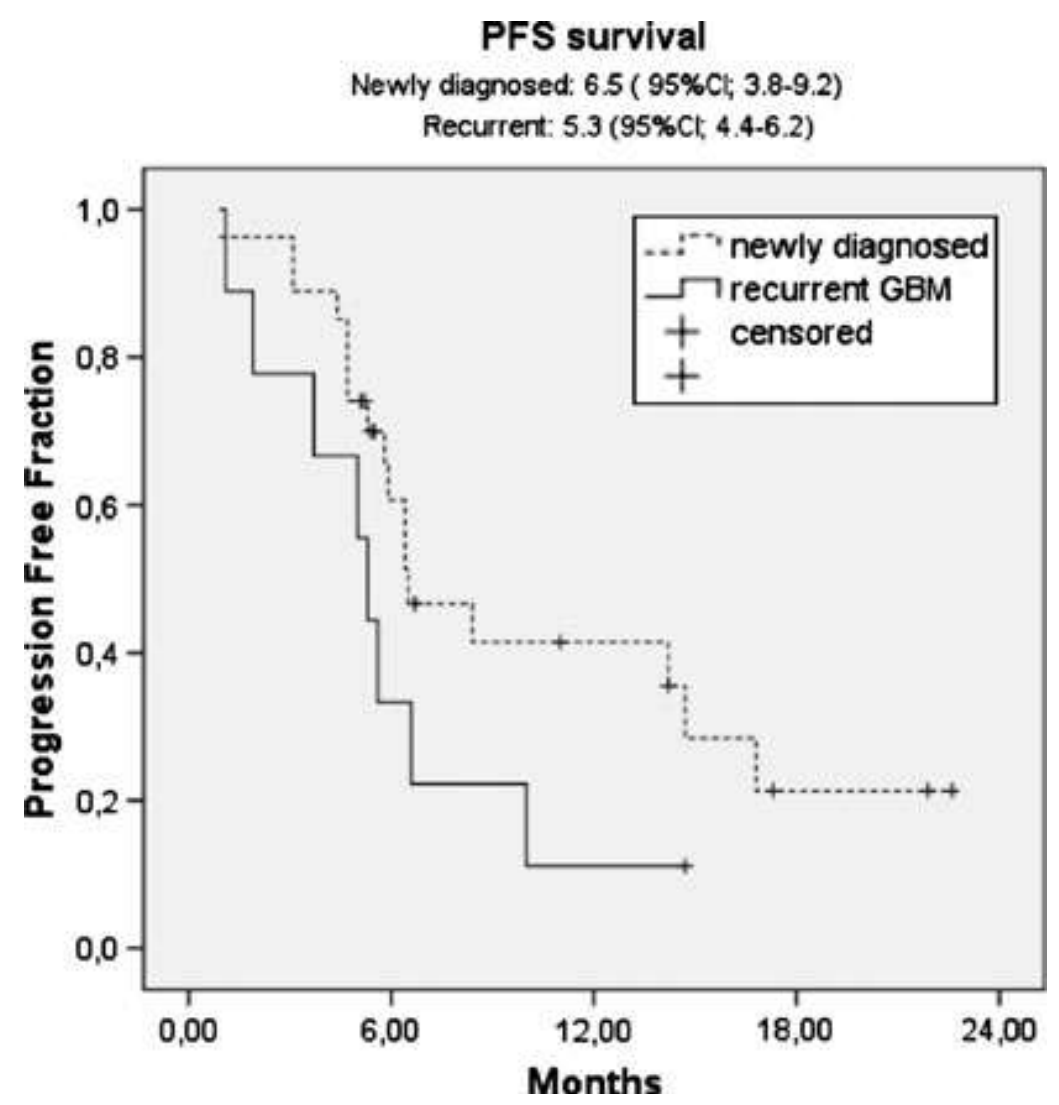

Figure 4. Kaplan-Meier progression-free survival curve.

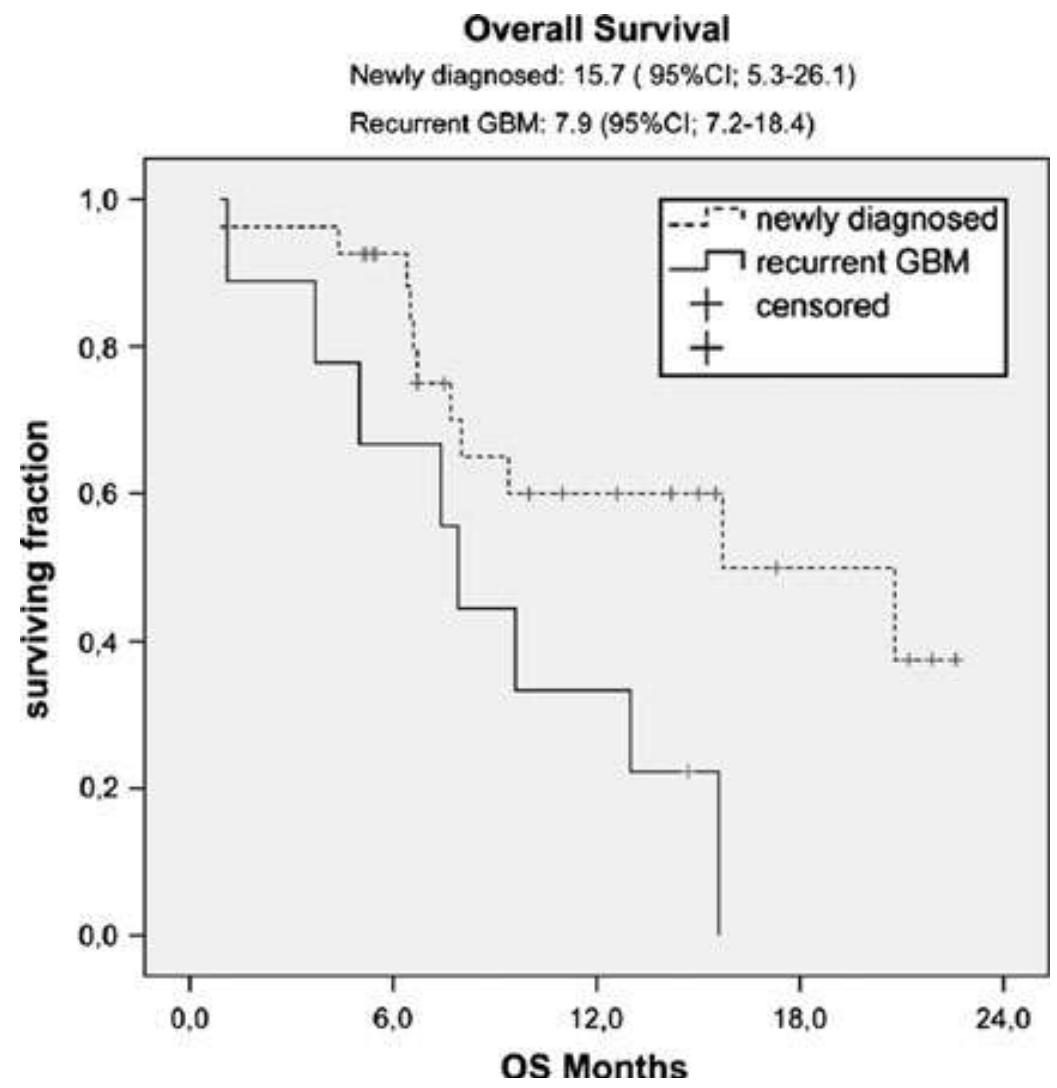

Figure 5. Kaplan-Meier overall survival curve. 